747

581 


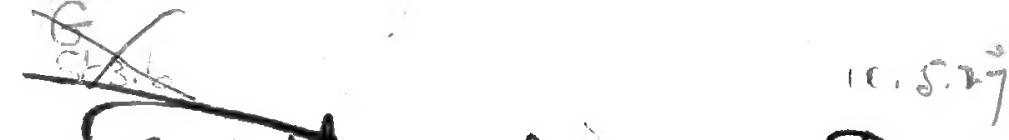

.

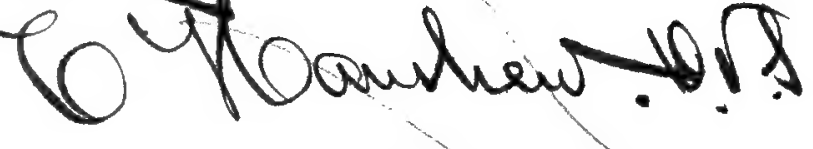

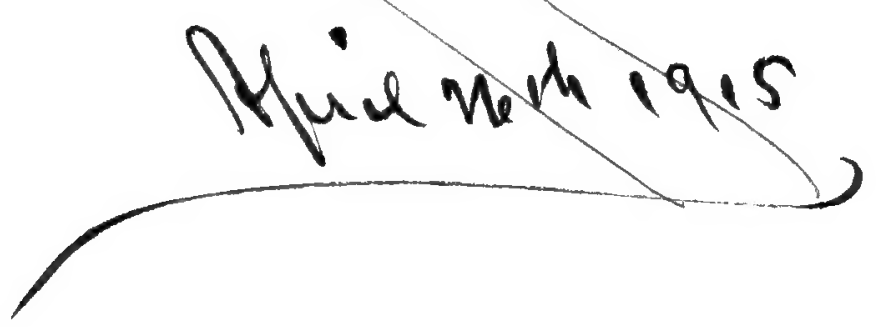

$$
\begin{gathered}
\text { PROPERTY OF } \\
\text { [E. HARE } \\
\text { IIZ5-127 D. W. S.] } \\
\text { BROOKLYN. N. Y. }
\end{gathered}
$$

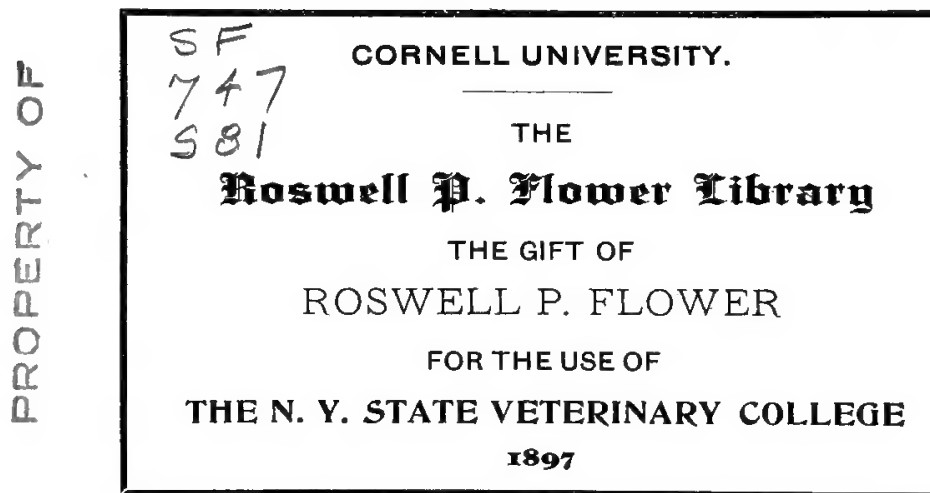




\section{SF 747.581}

Special veterinary therapy,

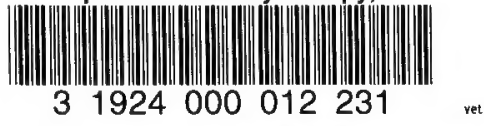




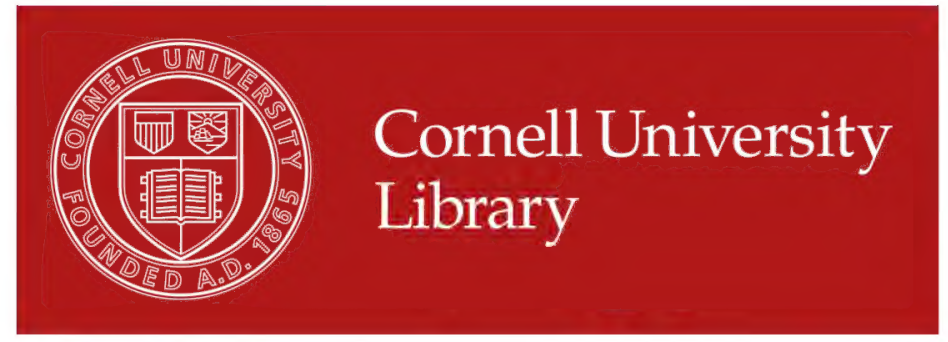

The original of this book is in the Cornell University Library.

There are no known copyright restrictions in the United States on the use of the text. 




\section{Special Veterinary Therapy}

By. Mart R. Steffen, M.D.C., V.S.

\section{DETROIT}

The Detroit Veterinary Instrument \& Supply Co.

$$
1914
$$




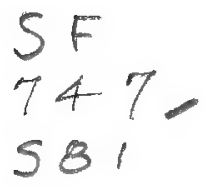

Copyright, 1914 By

D. M. CAMPBELL

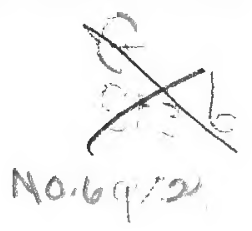




\section{Contents.}

Muscular Atrophy _.................................................... 7

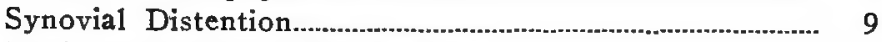

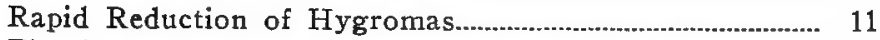

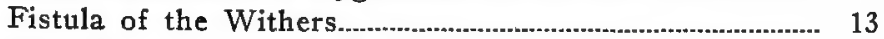

- Wire-Cuts-Lacerated Injuries................................................. 17

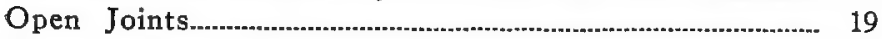

Chronic Laminitis.................................................................. 23

Hyperesthesia of the Neck

Chronic Eczema, Scratches, Grease Heel...…..................... 29

"Cracked" Heels in Track Horses.............................................. 31

Prolonged Analgesia in Ophthalmia

Specific for Infectious Entero-Hepatitis in Fowls........... 35

Occlusion of the Lachrymal Ducts......................................... 37

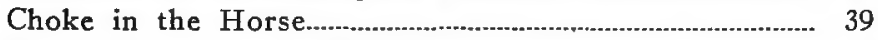

Hemorrhage from the Palatine Artery _........................... 43

Shortening the Duration of Parturient Paresis..._._........ 47

Obstetrical Paralysis in the Cow......._..._._._._......... 49

Protracted or Prolonged Colics................................................ 51

Intravenous Medication............................................................... 53

Subspinal Anesthesia for Abdominal Operations................ 55

The Treatment of Tetanus with Passiflora Incarnata........ 59

Contagious Abortion in Cattle.............................................. 61

Choke in the Ox

Paraplegia following Canine Distemper............................ 69

Treatment of Pneumonia with Sparteine Sulphate.............. 73

Creosote for Intestinal Infections......................... 75

Retained Secundines in Cows................................................ 77

Latent, Imbedded Foreign Bodies....................._......... 79

Botryomycosis ...

Chronic Edema of the Hind Extremities-Stocking........... 86

Pulmonary Emphysema_-"Heaves" ..................................... 87

Neglected Medicinal Agents in Veterinary Medicine ......... 89

Stock Colic Mixtures . ._.

Castration of Pigs Having Scrotal Hernia.......................... 95 
Fat paunches have lean pates; and dainty bits, Make rich the ribs but bankrupt quite the wits.

Shakespeare. 


\section{Introduction.}

This collection of therapeutic notes and clinical certainties has been gotten together as the result of more than ten years of active practice, during which period the writer's personal experience, as well as his deductions from the work of others, has been drawn upon and collated for the purpose of publication.

No system of medicine is upheld in this treatise; nor are the pathological or other technical phases of veterinary science given preference over the procedures of a definitely practical character, even though the latter border on the empirical. The end-result, the ability to relieve or cure, receives first consideration throughout the entire volume.

While the book will be most valuable to the recent graduate, it is confidently hoped and believed that it can also be used with profit by those who have long been engaged in practice.

The writer will be pleased to receive comments, criticisms or additions for possible incorporation in future editions.

Brillion, Wis. Mart R. Steffen.

December, 1914. 



\section{Muscular Atrophy.}

Muscular atrophy usually comes to the attention of veterinarians as a secondary affection, following laminitis, injuries, azoturia or as the result of prolonged lameness in one or more limbs. Cases of muscular atrophy from central brain or spinal cord lesions are almost unknown in veterinary patients.

For all cases of confirmed muscular atrophy, whether accompanied by lameness or not, we have in turpentine a panacea.

It is of importance to select only cases in which the inflammatory process in the muscle itself has subsided. In other words, atrophy must be confirmed and all evidence of inflammation must have disappeared before applying this remedy.

For this condition we use the rectified oil of turpentine, injecting it subcutaneously with a hypodermic syringe at several places in the upper half of the atrophied area. About five minims at each place are sufficient if the rectified oil is used, and at least one injection should be made at the extreme upper border of the affected area.

In high-strung animals, it produces considerable irritation and they may paw violently for eight or ten hours, at the end of which time the area is immensely tumefied. 
This tumefaction is gradually disseminated over a much larger area and is then slowly absorbed. In from two to three weeks no trace of it is left and in its stead good, solid muscular tissue is appearing. During this time the patient must have exercise, the best being a couple of weeks' run on pasture. If this is not convenient, light work should be given.

Much of the effect of the treatment is lost if the animal is idle during this time. If work is given, it should not be begun until the third day after the injections.

No abscess formation occurs if the rectified oil is used and the injection is aseptically made. In occasional cases some of the punctures may "point," but when they break or are incised it will be found that they contain only serum. If a pure rectified oil is used subcutaneous injection is ample. Intra-muscular injection is not satisfactory and entirely uncalled for. Abscess formation always follows intra-muscular injection and it does not accomplish enough additional good to offset the disagreeable features which it embodies. 


\section{Synovial Distention.}

These conditions occur in the various regions where synovial bursae are lodged and are frequently of such size as to detract from the market value of the animal. Many of these enlargements occur without apparent inflammatory disturbance and seem to be due chiefly to an over-active condition of the synovial membrane. In cases exhibiting positive inflammatory signs, lameness is usually present. The treatment of these cases varies with the location and severity of the lesion.

The cases which are under discussion in this article are those "puffs" of various kinds which come to the practitioner because they are "eye-sores" on the animal, detracting from his appearance of soundness and from his value as a marketable animal. Lameness is seldom present. For these cases we have in the following operation a simple and satisfactory treatment.

The operation is performed at the lowest point in the swelling, where an area of a square inch or two is shaved and thoroughly disinfected.

An aspirating needle is introduced and the contents of the sac are drawn out to the last drop. When this has been accomplished, the aspirating needle is carefully withdrawn and a very fine hypodermic needle is inserted at a considerable slant through the 
skin; it must not be pushed through the skin at right angles to it.

For the next step in the operation an ordinary rubber bulb and fine hose or a milk-fever outfit will suffice. The rubber tubing is attached to the head of the hypodermic needle and the cavity is inflated tensely with air. When enough air has been pumped in, the needle is quickly withdrawn and pressure is made on the seat of puncture for a few minutes with the fingers, after which a dressing of iodoform and collodion is applied. If the needle has been carefully introduced on a slant, no air will come through the puncture.

The results are obtained by the pressure which is exerted by the air on the cells of the synovial membrane, producing a degree of atrophy which inhibits excessive synovial secretion.

The air becomes absorbed in from twelve to eighteen hours. The patient should be kept quiet for a week. If the distention has not disappeared satisfactorily after the third week, the treatment should be repeated. 


\section{deupud

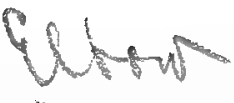

\section{Rapid Reduction of Hygromas.}

In contra-distinction to the various forms of "puffs" or synovial distentions discussed in the preceding article are the various hygromas that present features of genuine unsoundness.

While their location is always, like the various puffs, at the seat of a synovial bursa, we find here a real structural change. The bursa has been subjected to a severe bruise which has resulted in the formation of a solid mass of fibrous tissue.

The most common hygroma is that occuring on the point of the elbow and commonly termed a "shoeboil." The proper surgical operation for these is, of course, complete extirpation with the knife. However, as this operation makes absolutely necessary a long period of rest, during which time the owner is deprived of the use of the animal, it is often impracticable or at least possesses serious disadvantages. It is often highly desirable to remove or reduce these enlargements with the patient doing daily work. For such cases and for all hygromas, in fact, the following treatment is a very satisfactory proceding. The results are prompt and lasting and the animal can work while under treatment.

An area sufficiently large is shaved and thoroughly disinfected at the proper seat for lancing the tumor. All hygromas contain in their centre a cavity filled 
with degenerated synovia and occasionally some pus. The tumor is now incised for drainage, making a fairly large opening. The contents are forced out completely by compressing with the fingers and then an ounce or two of tincture of iodine is injected and allowed to run out again immediately. Following this a rapid reduction of the tumor is brought about by the use of Fibrolysin (thiosinamine salycilate), made by Merck \& Co., and marketed in ampules containing about 3cc each.

One injection is made as soon as the tumor has been lanced and thereafter every two or three days. Two ampules are used at each treatment, injecting it hypodermically at various points around the base of the tumor. Fibrolysin has a selective action on fibrous tissue and is of no value in enlargements of other tissues or organs.

A satisfactory, sometimes a complete, reduction of the hygroma can be obtained in the course of two to three weeks depending, of course, on its size. 


\section{Fistula of the Withers.}

This is a condition which requires the exercise of the best surgical judgment on the part of the veterinarian. It is just as important for the operator to recognize those cases which require a radical surgical operation and the complete extirpation of the diseased parts as it is to recognize the case in which ordinary drainage will suffice to effect a cure.

The guide in these cases is the amount of tumefaction which is present and the nature of this tumefaction. First, I desire to say that those cases which require radical interference are rare. Seventy-five per cent of all cases of fistula of the withers are curable through the establishment of proper drainage and the application of remedies to terminate necrotic tendencies. A possible addition is bacterin therapy but this is reliable and of real value only if the bacterins are autogenous. Many cases of fistula of the withers are distinctly of pneumococcic origin.

The treatment of fistulous withers consists of either radical surgical removal of all necrotic tissue or of the establishment of proper drainage only.

The first class, those for radical operation, consists of only those rare cases in which the withers are immensely tumefied with little or no discharge. In such cases incision is made on the median line and the entire mass of necrotic tissue, down to the last 
shred, is fearlessly dissected out. The surgeon must rely on his own ingenuity in controlling the profuse hemorrhage which always occurs and can not be avoided.

The rapidity with which recovery takes place after this procedure depends upon how thoroughly the necrotic area is cleaned up and upon the after-treatment.

The after-treatment in these cases should consist in packing the cavity daily with sterile gauze, and only such irrigation or washing as is absolutely needed. During this time tonics should be given and the horse should be kept as quiet as possible. Occasional swabbing with tincture of iodine helps to hasten granulations.

The radical operation for fistulous withers is far from being a scientific or pleasant operation; it is to be used only in cases which demand it. Again, such cases are rare. In most cases drainage and proper medical care effect a cure in a reasonable time and ordinarily this is the only satisfactory method in general practice where hospital care is not available.

There are not many cases in which drainage, proper drainage, can not be obtained. The point to select for making an opening to drain the withers is always at the conjunction of the normal level and the tumefaction. This means that the mouth of the opening is always in healthy tissue. Therein lies the secret of cure of fistula of the withers by drainage. At first thought, this appears a simple matter, but, for me, it requires considerable study and careful examination 
in every case to pick out this decidedly limited area. The incision must then run horizontally and must be at least two inches wide through skin and underlying musculature. From this incision a stab-wound is then made through the tumefied parts running obliquely upwards towards the normal apex of the withers, not stopping until the top is reached just under the middle line. (The two-inch incision is made with a sharp scalpel through the skin and subcutaneous tissue. A stab is then made with a long abcess knife from the mouth of this incision, obliquely upwards and inwards, until it reaches the normal apex of the withers.) This stab-wound is then widened laterally with a long, straight probe-pointed bistoury. This drainage must always be made on both sides, even if the condition is apparently, confined to one side only.

When these openings have been made as directed the first treatment is given at once consisting of thorough irrigation with a ten per cen solution of chromium trioxide. This is done most satisfactorily with a fountain syringe, using a long nozzle, which can be inserted in the wound far enough to reach nearly to the top of the withers.

Chromium trioxide is the remedy of choice here. It stops sloughing and odor almost immediately and its action is painless.

When the first treatment has been given, both openings should be snugly packed their full length with gauze, which is allowed to remain for eight or ten hours. It is then removed and the wounds are allowed to remain open. Subsequent treatment con- 
sists in irrigating the tracts once each day with a three or four per cent solution of chromium trioxide, following this irrigation every time with one of plain, sterile water. After ten days or two weeks these irrigations are made only every other day, and at proper intervals an iodine solution is used in their place.

Unless the case is an exceptionally severe one, all traces of pus and necrotic tissue will have disappeared at the end of four weeks and only one or two per cent solutions of the chromium salt are then used, and at intervals of three days. About this time, the external surface of the withers also is to be painted every two or three days with tincture iodine U. S. P. It is only very rarely that a case resists this treatment and as a rule complete recovery comes in five or six weeks. If autogenous bacterins are used at the same time this can be shortened considerably.

With this treatment, the surgeon can hasten matters considerably during the first week or two by careful and gentle curettage in the necrotic area, removing gently any portions of tissue which are loose or tending to become separated. If the primary incision is made full two inches wide, a good opening remains until treatment is terminated. 


\section{Wire-Cuts-Lacerated Injuries.}

Wire-cuts and similar injuries are serious only when important structures such as the articulation, tendons or other parts equally vital are involved. Lacerations of the fleshy parts can be of very great extent without producing serious results. Dangerous infections in such wounds are exceedingly rare because the wound is usually open and gaping.

In cattle such injuries are always to be sutured. Healing is prompt and stitches hold. In the horse, with few exceptions, suturing is a waste of time and the open treatment is best. When tendons are severed, it is of importance to consider the patient's disposition before attempting to re-unite the ends by suture. A colt with an intractable disposition will not submit to applications for immobilizing a limb, especially a hind limb, and without immobilization, suture of a tendon is useless. In the end, and on the average, just as good results come from the open treatment even in such cases.

With the following treatment ninety-nine per cent of wire-cuts encountered in usual practice will heal promptly with but little scar formation.

F

Kalii Permanganatis 'C. P................ 3 iv Aquae Destillatae............................... 5 viij M. Sig.-Apply two or three times daily with a small brush, painting over the wound repeatedly each time until the tissue assumes a blackish color. 
If properly applied no excessive granulations (proud flesh) ever appears. This should be kept right up until the wound is entirely healed. It is surprising how little scar will remain from a very severe cut when this treatment is used. By keeping the wound surface seared with this caustic solution, no flies will bother and no further treatment is required. As the potassium permanganate will not dissolve entirely in the proportions given above, a "shake" label should be put on the bottle. 


\section{Open Joints.}

These will be considered in two parts, namely, those of recent origin in fresh wounds and those of a chronic or subacute and infected character.

1. Fresh Wounds, Lacerating a Capsular LigaMENT. It frequently happens, as the result of accidents, that an articulation is involved in the trauma. While all accidental wounds in veterinary patients are to be considered surgically unclean, it is well not to carry this theory too far. Unless much extraneous matter such as hair, chaff, etc., has entered directly into the articulation, do not allow antiseptic solutions to penetrate to the synovial surfaces when cleaning up such a wound.

Swab the surrounding parts as clean as possible with cotton, but do not allow any of the solution to reach the joint. (Nothing seems to irritate a synovial cavity more than water.) After the surrounding parts are thoroughly swabbed and dried with clean, dry cotton, the wound cavity is completely filled with powdered natrium bicarbonate, C. P., some of which is even gently pressed so as to enter the synovial cavity. It is important that enough be used. A thin layer of cotton is now made to cover the lesion and retained either with collodion or bandages.

This dressing should be allowed to remain for twenty-four hours. At the end of that time it should 
be removed and the wound carefully inspected for synovia. No instrumentation is permissable; the inspection is confined to looking into the wound for traces of synovia. If no synovia is to be seen the wound is treated along regular lines; ordinarily as described for wire-cuts.

If synovia is present in the wound, the treatment is repeated as on the first occasion and again left on for twenty-four hours. More than two such applicaions are seldom necessary and unless the wound has been very large and is very severely infected, good healthy granulations and no synovia are present after the first twenty-four or forty-eight hours.

2. Chronic, Infected, Purulent Joints. The treatment of these is radical. While it happens now and then that cases of this kind recover with dilatory methods of treatment, it is only by radical procedure that prompt and positive results can be obtained.

The various articulations of the equine present varying degrees of severity and obstinacy in this affection. The elbow joint stands at the head of the list of fatal terminations. I would class the coffin joint second; next in order I would place the hock; last, the stifle.

The following method of treatment is always successful in cases in which the patient has not become greatly emaciated and still retains the greater part of his vitality and good spirits. It is successful in fifty per cent of the latter cases but it is of no avail (nor any other treatment) in cases where the patient is down and refuses to eat. Such cases rally occasionally 
for a temporary period, only to go down again later and die. If the surgeon will select for this treatment cases that are, while moderately grave, still in good general condition, or even fair, he can promise his client good results.

To carry out this treatment properly, it is essential to cast the patient, either on the ground or on the table. The following procedure is then adopted:

Thoroughly cleanse the region of the joint involved, shave and scrub. Irrigate the joint cavity for at least ten minutes with a solution of hydrargyri chloridum corrosivum 1 to 3000 at body temperature. This must be done with the utmost antiseptic precautions and great delicacy. If the opening in the joint is in such a position that good drainage can not be obtained, another opening is to be made surgically at the desired point.

Having thoroughly flushed the joint cavity with the solution, for which purpose a fountain syringe is best, it is again flushed for a considerable time with plain sterile physiological saline solution at body temperature. These washings are only to be discontinued when the fluid comes out clear and free from pus flakes or detritus. It may take a half hour of continuous irrigation to accomplish this: When this has been accomplished the interior of the joint may be considered surgically clean and it is now immediately injected with the following suspension:

P

Hydrargyri Iodi rub.

O1. Olivae Purae

M. Sig.-Shake before using. 
This should be injected into the cavity slowly after plugging up all openings, except the one through which it is to be injected and be sure every portion of the interior comes in contact with the suspension.

As soon as this is done the entire joint is swathed in clean cotton held in place by such bandages or retaining appliances as the surgeon's ingenuity may devise. This dressing should remain in place for two weeks.

In nine out of ten cases a complete cure will have been effected when the dressing is removed at the end of this time. In rare cases it may be necessary to repeat the treatment.

It is very imporant that the entire joint be heavily swathed in cotton which must be held snugly, yet not tightly in place.

The patient must be kept as quiet as possible until the two weeks have elapsed, and during this time should receive a dram of hexamethylenamine in a pail of drinking water three times daily.

Hexamethylenamine is of much value in various forms of arthritis. It has been found that it is excreted by serous membranes and it has been demonstrated to be present in synovial cavities within an hour or two after administration. Its antiseptic action is due to formaldehyde which is liberated during the process of elimination. 


\section{Chronic Laminitis.}

Cases of chronic laminitis as a rule come to the practitioner "second-hand," that is, after some other practitioner has been unsuccessful in satisfactorily terminating an acute laminitis.

Usually, in these cases, anatomical changes have occurred in the foot that, in themselves, are beyond repair. These changes vary from the ordinary dropped sole to perforation of the sole by the os pedis with concomitant conditions, the result of infection and bruising. At best the latter cases are in a pitiable state, and it is doubtful what sort of prognosis should be given.

The most common cases of chronic laminitis which come to the practitioner, present considerable lameness and the ordinary dropped sole. For these cases, we have in potassium iodide almost a specific. It should be given in one dram doses in solution, one dram three times daily, for an indefinite period.

At the same time the mixture given below is to be applied in the coronary region once each day with a stiff brush, keeping the applications up for two or three weeks.

$\mathbf{R}$

Tr. Cantharides.

O1. Cajuput.

O1. Terebinth

Tr. Iodine

a.

M. 
Attention must be given to shoeing and a rest of several weeks in a well-bedded box-stall is helpful. If the sole is "dropped" to a considerable extent, heavy leather should always be applied between the shoe and foot; or better still, a protection band of iron should run across the bottom of the foot between the sides of the shoe. This band must not quite touch the sole. 


\section{Hyperesthesia of the Neck.}

This condition, sometimes termed "crazy" sore neck, is well-known among veterinarians and affects only work-horses. It appears in two forms; one in which the neck appears to be only slightly sore at the collar seat; the other, in which there is a plug or wedge of necrotic, dry tissue in the centre of the region.

The first form is the most difficult to terminate. The horse, when an attempt is made to put on the collar or take it off, becomes literally crazy; he attempts to kick, strike, rear up or bite; in many cases becoming well nigh unmanageable. While these cases usually begin with an ordinary "sore neck," the animal seems to retain his "crazy" disposition even after the parts have been healed up and no trace of "sore neck" is evident.

The second form, in which there is present a plug or wedge of dead tissue, is easily brought to a favorable termination. Surgical removal of the dead mass, (which usually has the appearance of horn and may be several inches in length and imbedded deeply) and then treatment of the wound puts an end to the trouble.

In the first form, however, there seems to exist a genuine hyperesthesia of the neck region and a severe underlying dermatitis is always present. The only 
evidence thereof is a slight fullness or thickening, with local heat. Occasionally cases of this form occur which are only cured after the animal has been given a protracted rest from service in the collar. It is possible, sometimes, to accomplish much by substituting a breast collar.

Cases in which the horse shows no especial vicious disposition, usually terminate favorably with a few weeks' treatment with Prof. A. H. Baker's 'toughening lotion." This is applied two or three times daily with the hand, thoroughly painting the entire collar seat with it. It is made by dissolving two ounces of tannic acid in six ounces of dilute acetic acid and two ounces of powdered alum in six ounces of water. Mix them and it is ready for use.

A zinc-lined pad should be used for these cases.

In the more desperate type of these cases, in which the foregoing treatment has not accomplished anything, an entirely different procedure is necessary. The deep, underlying dermatitis in such cases is not benefited by topical applications. From various salves, lotions and other treatments which have been applied, the epidermis has assumed a tough, pachydermal character and local treatment is useless. Such cases are cast, either on the ground or table, and the epidermis is shaved off the entire region with a sharp sage knife. Oozing of blood must be the guide for the depth of the shaving. It is well to have several sharp knives at hand.

When shaving process has been thoroughly gone through, having paid special attention to the bottom 
of the folds in the skin, the entire region is swabbed with mild bichloride solution until all bleeding has stopped. This is important; all bleeding must be stopped before the next step is undertaken.

Having previously made a saturated solution of iodoform in ether, which should be contained in an atomizer, the whole bare area is freely sprayed therewith; it dries at once and leaves a solid coating of iodoform.

This is allowed to remain for twenty-four hours, after which it is washed off with ether and the neck is then treated daily with the toughening lotion as given above for ordinary cases.

This method is nearly always successful. In horses that are naturally mean or vicious, a variable period may elapse even after this treatment before they are again entirely docile in this respect.

In occasional cases good results follow the internal administration of Fowler's solution in small doses for a prolonged period. A zinc pad does much good in all cases. The use of deer-skin and other hairy or wooley pads should be discouraged on general principles because they are insanitary and almost impossible to keep clean. 



\section{Chronic Eczema, Scratches, Grease Heel.}

It is not necessary to dwell on the symptoms of these conditions. While very common and readily recognized their obstinacy to treatment is equally well known.

In all cases thorough washing with soap and warm water should begin the treatment, but after this no further washing should be done. A very important point in the subsequent handling of the case lies in keeping the parts dry.

Having thoroughly cleansed the parts, the following mixture is applied with a small brush morning and evening until healing has begun. Usually a week or ten days suffices for the first course and twelve ounces of the mixture is about the quantity required.

H

Hydrargyri Chloridimite................ 3 i

O1. Cajuputi

O1. Gossypii Semen.................... s. 3 xij

M.-Shake the first two ingredients together vigorously before adding the third. Apply as directed above.

When this has been used the parts have a healthy tone and the cracks and ulcers show nice, healthy tissue. 
The treatment is carried to termination with the following:

B.

Tr. Benzoin Compound.

Tr. Iodine ...........................................aa $₹$ iij

M. Sig.-Apply with a small brush morning and evening.

In most cases this completes the treatment and leaves a smooth, velvety area of skin. In occasional cases the skin has not become quite smooth when the last mixture has been used up and in these the treatment is completed with the following:

$\mathbf{R}$

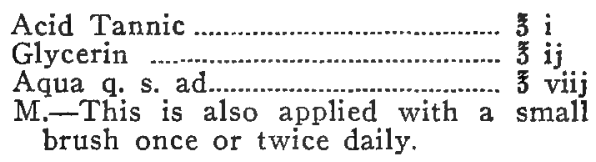

In well developed cases of grease heel put the patient on a course of potassium iodide. If this is not practicable use strepto-bacterin. Some cases of "scratches" are attributed by some authors to variola. It is doubtful whether this is correct. The matter requires further investigation. 


\section{"Cracked" Heels in Track Horses.}

This is a condition peculiar to speed horses and is an aggravated form of eczema, presenting deep cracks or furrows in the hollow of the heel. It is apparently the result of the all too frequent leg washing to which these horses are subjected. The various solutions and water collect in the cup of the heels that are afterwards improperly dried.

Therefore the first requisite to a successful termination of treatment, is the discontinuance of such washing or at least that the leg wash be given in such a manner that the fluid will not come in contact with the cracks. Most of these cases are chronic, and of long standing when they come into the veterinarian's hands. This is an important point to consider in their treatment. The edges of the cracks are hard, indurated and have almost a fibrous appearance.

Treatment should commence with careful curettement of the edges and sides of the cracks. While carefully and cleanly done, this curetting must be done thoroughly, scraping off all hardened tissue and producing in effect a fresh wound.

When this has been done, the parts should be covered with a mercury bichloride solution 1 to 2000 , packed and bandaged. This dressing is allowed to remain in place for eight or ten hours. It is then removed and the cracks thoroughly swabbed out with 
dry cotton. Then the following mixture should be applied three times daily until healing is complete, which takes two or three weeks as a rule.

P.

$$
\begin{aligned}
& \text { Balsam Peru ................................... } \\
& \text { Tr. Benzoin Compound...................... } 3 \text { ij }
\end{aligned}
$$

This amount is used for each foot at each application and is heated slightly over a match. It is then poured, warm, into the cracks. If granulations are slow or lack vitality, a light cauterization with silver nitrate or stimulation with pure tincture of iodine once or twice will hasten them. In exceptionally stubborn cases, a red iodide of mercury and cantharides blister should precede all other treatment. 


\section{Prolonged Analgesia in Ophthalmia.}

In most of the ailments of the eye of the horse, that are serious enough to require treatment, the great amount of pain and photophobia present are obstacles to the examination and manipulation required. The animal forcibly resents any attempts to examine the injured optic and even the application of the twitch does not help matters much.

It is not practical and rather costly, to instill a cocaine solution and too often a careless examination is made and an eye lotion prescribed.

By following the plan which I shall outline it is possible to relieve the excessive pain in a few minutes, after which the animal will usually open the eye fully so that a careful inspection may be made, and if further examination, with a speculum, is necessary, the animal resists but little or not at all.

The procedure consists of first removing all traces of mucous or other discharge with a cotton swab and sterile water. When this has been done, a one-grain hypodermic tablet of quinine-urea hydrochloride is placed into the conjunctival sac at the inner canthus. It dissolves quickly, promoting a flow of lachrymal fluid and apparently produces an anesthesia of the entire organ and membranes. Within ten or fifteen minutes the animal will open the eye freely and ap- 
parently is free from pain. This analgesic effect lasts for several days.

In addition the quinine-urea hydrochloride seems to exert an antiseptic and astringent power which will quickly terminate ordinary inflammations of the eye. In corneal ulcer this effect is especially striking.

To obtain the best results it is of great importance to use only sterile water in cleaning the eye before inserting the tablet. No antiseptic solutions should be used. 


\section{Specific for Infectious Entero- Hepatitis in Fowls.}

There is no doubt in my mind that we have in potassium dichromate a specific for this disease in every sense of the word. It is not only curative; it is also prophylactic.

In a number of flocks in which this treatment was used in three different epiornithics, the results were so satisfactory in every respect that it deserves notice. In all cases the outbreak terminated promptly; sick hens recovered and hardly ever a new case developed after the treatment was begun.

The potassium dichromate should be given in the drinking water, dissolving it in the water in the proportion of about six grains to the quart. A fresh solution should be made twice a day and the hens confined for five or six days so that they will not have access to any other water during this time. With this strength of solution, the hens will get from oneeighth to three-eighths grains during the day's drinking estimating from one to one and one-half ounces of the solution per hen, which is high.

Sick birds which will not drink should be given a teaspoonful of the solution every three hours during the day. 
Although this disease is supposed to affect turkeys chiefly, it is far more common among chickens than is generally presumed. It can easily be demonstrated by post-mortem examination.

Whenever the disease has gone through a flock the hen house and all accessories should be thoroughly renovated. If this is not done, isolated cases in an atypical form may make their appearance indefinitely.

In this as in all contagious or infectious diseases, isolation of the sick helps to curtail the outbreak considerably. As soon as a bird shows signs of the disease it should be taken out of the flock. 


\section{Occlusion of the Lachrymal Ducts.}

As a pathologic entity, this condition is easy to diagnose. Partial and complete occlusion occurs sometimes with severe conjunctivitis and other severe inflammations of the eye and appendages. In such cases the duct nearly always resumes its function and becomes pervious again with the recovery of the patient from the exciting cause, whether it be a conjunctivitis or some other disease.

When, however, we have occlusion of one or both lachrymal ducts as a primary condition, we see a clinical picture which is characteristic.

The eye itself and the conjunctiva appear normal; nothing abnormal can be seen even by careful examination. The eye is only. partially open and a constant stream of lachrymal fluid is making its escape from the edges of the lids. The nasal opening of the duct is dry. When the horse is brought into bright light, constant blinking is gone through, very much like a person just awakened.

With few exceptions, these cases are due to a thickening of the membrane lining the duct as a result of catarrhal inflammation. The usual procedure of catheterizing and then irrigating the duct, the teaching of our text-books for this conditoin, is far from satisfactory and very impracticable. In fact, in general 
practice it can hardly be carried out without inflicting additional injury to the delicate parts involved.

The treatment described below has been used successfully since 1908 and if carefully and persistently carried out a cure can nearly always be abtained within a reasonable time, usually four weeks.

One of the important steps in beginning this treatment is to give explicit instructions to the person in whose care the animal is while under treatment, as regards the great delicacy and absolute cleanliness with which the eye must be handled. Too much stress can not be put on this point. The average horseman uses very poor judgment in this respect.

The treatment begins with a very gentle removal of clots of mucus from the inner canthus. Some of this is always present and a clean piece of absorbent cotton is to be used for this purpose. Following this, a lump of two per cent yellow oxide of mercury ointment of about the size of a grain of corn, is gently placed in the eye at the inner canthus and the lids gently pressed together with the fingers.

This is done once each day until recovery occurs, and every second or third day an innunction is made on the course of the facial portion of the duct, (that is, from just below the eye to within a few inches of the nose) with half strength mercurial ointment. This should be gently massaged in over the approximate course of the duct.

If it is desired to hasten recovery, a course of iodide of potassium will be helpful. 


\section{Choke in the Horse.}

If there is a condition in veterinary practice in which the veterinarian must demonstrate tact and absolute control of the client (not the patient) this is certainly the one.

In all these cases the owner or attendant is to be taken in hand firmly. Often times this requires as much judgment on the part of the attending surgeon as the treatment of the case in hand. Usually they have heard of, or seen used, probangs, (buggy-whips, broom handles, traces, and what-not in the form of probangs) and they want an immediate demonstration of similar tactics. They want to rub and massage the neck, pour into the animal quantities of oil, and to do a thousand and one other things.

Ninety-five per cent of all chokes are really very benign conditions when treated early. In many cases it is the treatment administered that transforms the case into a really grave one. I do not fear contradiction when I say that nearly all chokes would be relieved spontaneously if the horse were at once placed where he could get nothing whatever to eat but plenty of water to suck up. In esophageal choke the water taken is usually "sucked" tentatively.

The pathology of nearly all chokes is confined to esophageal spasm. In exceptional cases a jabot or more or less permanent dilatation may exist previously and remain permanently. 
Most of the chokes we meet in general practice are sporadic cases, and never recur; therefore the habit of attributing all cases of choke to previously and permanently existing dilatations not only is not borne out by practical evidence, but is misleading. If this fallacy be firmly grounded in the surgeon's mind, his treatment will be in gross error. Just as soon as the veterinarian treats his cases of choke with the understanding that they are almost without exception due to a spasm only, a tonic spasm of the esophagus, he begins to have prompt and very satisfactory results. As long as he is possessed of the jabot or dilatation theory as a factor in choke he has trouble with them, because he undertakes to do too much,

When called to a case of choke in the horse, the veterinarian must keep himself well in hand and must not allow himself to become biased by the owner's or the attendant's perspective. Make up your mind firmly that you are handling a very simple functional disturbance and proceed to place your client in the same frame of mind. When you succeed in doing this you have your case fifty per cent cured.

If a box stall is available, have the horse put there; if none is available, allow him to remain in the single stall. But in either case, see to it that the floor, manger and feed box is absolutely freed from feed of any kind; use a broom and sweep them clean. When this has been done, a large pail or a tub of water should be placed where the horse can reach it without any special effort on his part. When this has been done the veterinarian should administer from one to two 
grains of pilocarpine hydrochloride, hypodermatically. As soon as salivation starts from this injection, usually in five to ten minutes, the veterinarian and all others can serve the patient best by going away and leaving him alone. In a good deal more than half of all cases of choke, all evidence of its existence has passed off at the end of three hours following this line of treatment.

When the surgeon again visits the patient (three or four hours after giving the pilocarpine is a good time to call again in these cases) he should attempt to make the animal go through several acts of deglutition. If the horse on these attempts swallows without arousing the characteristic gurgling and spasm of the muscles in the cervical region he may consider the case cured. However, nothing but water and a very thin bran-slop should be allowed for at least twelve hours more.

In the event that the choke is not relieved by the treatment thus given, it is not yet time to get excited by any means, especially if the choke is in the cervical region where it may be relieved by an operation if everything else fails. Here I desire to say that I have yet to see a case of equine choke due to spasm of the esophagus, which resisted patient and simple means of treatment, such as given above. Occasionally one of these cases will "hang on" for twentyfour or forty-eight hours, when suddenly the animal swallows normally and is well.

In the event that recovery has not taken place after three or four hours from this treatment, I have 
used successfully, for a number of years, an injection of one grain apomorphine, hypodermatically. The horse is still retained in a clean stall free from feed, and water is kept constantly before him. After the injection of the apomorphine, five or six hours are allowed to elapse before anything further is attempted. Should the choke still be in evidence at the end of this time (a very rare occurence) the surgeon can begin to think of operating. Talk to your client and prepare him for what you may have to do, but do not do it yet. Allow another five or six or even ten or twelve hours to pass with the horse kept in a clean stall as before. The chances are that you will be very pleased over your good judgment at the end of of this time; your client will be even more so.

If you should be so unfortunate as to meet with a . case of real jabot, (that is what you undoubtedly have when the foregoing procedure fails) your patient is just as good a subject for the necessary operation, if you have hot allowed him to swallow any food since he became choked, as he was when you first saw hin. You have used good, sound and expert judgement and have not harmed your client nor his horse. You have given them both every possible chance.

Then operate according to the directions given by Merrillat.

Here I can promise the surgeon that his operations for choke in horses will be few and far between if he follows patiently the instructions outlined above. 


\section{Hemorrhage from the Palatine Artery.}

Hemorrhage from the palatine artery is always serious, requiring prompt and efficient measures for its control. How disagreeable a task it is, to treat such an occurrence can be learned only from experience. However, one case is usually enough to demonstrate this part of the matter.

The veterinarian who has had the good fortune, (or possibly misfortune would be the better term) to treat several of these hemorrhages soon makes up his mind that it is far from being a simple matter. The teaching in college and in our text books on this subject has been far from satisfactory and is really worthy of but little notice.

As with so many other apparently trivial conditions, hemorrhage from the palatine artery is given but little attention in the various departments of surgery. The fact is that this hemorrhage is a true clinical entity, occuring with more or less regularity in a quite typical form. This is especially true in localities where old time empinics still predominate, and "bleeding" is resorted to for most ailments. Probably ninety-five per cent of all cases of hemorrhage from the palatine artery which come into the veterinarian's hands are the result of empirical treatment either by 
the owner of the horse or by non-graduate veterinarians; such as cutting "lampas," bleeding for colics, for sun-stroke and what-not. Rarely a hemorrhage of this kind occurs accidentally, but nearly always it is brought on by some such ignorant practices as those enumerated above.

The first thing of importance to learn about the control of bleeding from this artery is the fact that it can almost be turned into a pleasant and somewhat scientific job if the horse is first cast. It is not necessary to make a preliminary examination. From the history given you by the client you can tell just what you have to deal with, and the first move on the veterinarian's part should be to cast the patient as promptly as possible.

Bandages, compresses, tourniquets, styptics and all other mechanical agents have no place in the treatment of this condition. A curved needle, heavy, braided silk and a good needle-holder are the weapons with which to fight this rapidly fatal injury.

When the horse has been cast a man is instructed to kneel on the animal's neck, just behind the ear, grasp the muzzle firmly with both hands and turn the nose upwards.

If a speculum is at hand it should be in place as it makes the performance of the veteninarian's part more simple. If no speculum is available, the assistant holding the head must firmly grasp the tongue with one hand; drawing it tensely out and against the cheek. The veterinarian now locates the incision or the tear in the palate from which the hemorrhage cowes; 
by swabbing with a thick wad of cotton he can do. this easily.

Having located the opening, one interrupted or ordinary stitch is put through the soft tissue of the palate transversely across the trauma (note I say. transversely across the traumu, not the artery) and as nearly over the course of the palatine artery as possible. It is not necessary to engage the artery in the stitch. The stitch is then tied "good and snug" but not too tight.

In most cases of this kind, resulting from the "bleeder's" knife, this one stitch is sufficient and the hemorrhage stops immediately. Reference to physiology and to histological anatomy explain the reason for this moduis operamdi.

It is indeed rare that a case is presented which requires more than one stitch if it is properly and correctly placed. Care must be used in starting the needle so that it is not buried too deeply and the point broken on the hard structures above. Aim to bury the point about one-eighth of an inch and bring it level with the surface for a considerable distance under the hard palate (depending on the width or "gape" of the cut) before turning it upwards again to engage the other side of the wound. In other words, the suture should go in and come out at least three-eighths of an inch from each edge of the incision. A fullcurved needle and medium-heavy braided silk should be used. A needle holder is almost indispensable.

It is possible to carry out this little operation without casting the horse; but in this position it is about 
the most disagreeable, bloody piece of work in veterinary practice. It is almost impossible to hold the animal's head still, the awkward position in which the work has to be performed and the constant slinging of blood by the movements of the head and tongue make it far from pleasant.

Much time can be saved, (as well as wear and tear on the veterinarian's temper) and a better operation performed by casting the horse in the beginning.

No attention is given the stitch for at least twentyfour hours thereafter. On the second day it and the parts around it are sprayed or swabbed with tincture of iodine and on the third day it may be removed. No harm results even if nothing further is done and the stitch allowed to slough out.

In some of these cases the animal is almost exsanguinated by the time the veterinarian arrives and gets the hemorrhage under control. It is always well to administer restoratives and put the animal on a course of iron and other tonics for several weeks. 


\section{Shortening the Duration of Partur- ient Paresis.}

The treatment under discussion has for its object more rapid recovery in cases of milk fever. It is not a treatment in itself, but a measure supplementary to the distention of the udder with air.

It frequently occurs that cases of parturient paresis progress rapidly and favorably to a certain stage and then no further progress towards complete recovery seems to be made. The cow lies upon her chest, appears bright but refuses to get up. If a sufficient period of time is allowed, say two or three hours more, she eventually gets up. However, the veterinarian in general practice would like to see the patient on her feet before leaving her. Two hours is not too long to remain with a case of this kind, especially if results can be fully accomplished in this time.

The treatment which I can highly recommend for this purpose was discovered through efforts on my part to bring about a rise of temperature to normal. It is a clinical fact, despite teachings to the contrary, that with few exceptions these cases have a subnormal temperature. I have made it a regular practice to take the temperature in cases of parturient paresis and I am positive that nine out of ten have a sub-normal temperature, ranging from $96^{\circ}$ to $99^{\circ} \mathrm{F}$.

Along this line $I$ have demonstrated that as soon as the patient's temperature approaches the normal there is no trouble about getting her to stand up. We 
have little or no trouble in calling to mind agents which will reduce the temperature; most of us can name a half-diozen with hardly a thought. But, let some one ask us for something out of the materia medica which will quickly and quite surely raise animal temperature! That makes us think.

Atropin will do this, will do it certainly and promptly. Before I adopted this line of treatment, my method in parturient paresis, after inflating the udder, was to give from a quarter to a whole grain of strychnin hypodermatically.

I have now discarded the strychnin injection for one of a quarter to a half grain of atropin sulphate. The consequence is that where I used to make several visits to these cases, hardly ever getting one to arise short of six hours, I now remain with the case just about two hours and nearly every time the cow is on her feet before I drive away. Occasionally one refuses to respond, but after using the treatment a few times, it will be quite easy to pick out those cases. Those in which the symptoms of coma remain over an hour and are slow to brighten up will take a somewhat longer time. A few cases will teach this.

My method is to inflate the udder and then give the atropin. When this is done, I have the animal virtually smothered in all the blankets inthe stable. I take the temperature every fifteen minutes. As soon as it approaches normal an attempt is made to make the cow get up, assistance being given by the tail. The quickest recovery I have obtained in this manner was in one hour and thirty minutes. 


\section{Obstetrical Paralysis in the Cow.}

This is a condition which follows only those cases of parturition in which the calf is exceedingly large, or cases of dystokia, during the correction of which the cow is subjected to prolonged handling and bruising. It is rarely, if ever, seen after normal delivery or after cases of minor dystokia.

The ideal circumstances for the development of this condition consist in prolonged labor due to an abnormally large fetus. The usual history is that the cow was down during the birth and has not been able to get up since, or that she went down very soon after the calf was delivered and is unable to arise.

These cases can not very easily be confused with parturient paresis because the entire symptomatology in obstetrical paralysis is confined to the inability of the cow to get up. In every other way the animal is normal; no sign of coma or indisposition in the least. The animal eats and drinks and looks well in every way. The most careful examination will bring out nothing of value in diagnosis, except that usually the tumefied condition of the vulva gives evidence of the difficult labor.

The history in these cases determines the diagnosis: A very large calf; much pulling; long time in effecting delivery. Sometimes these cases supervene on cases of dystokia which the veterinarian himself has been called to relieve and it is on this point that I want to call especial attention in this chapter.

It has been my experience that obstetrical paralysis will not develop in these cases where the cow, if 
lying when delivery is effected, is immediately made to rise. Every means must be used to get the animal upon her feet at once and when this has been done, someone should remain present to see to it that she remains up for at least two hours, during which time a little walk should be given every twentyminutes.

If the cow is on her feeti when the calf is delivered every effort should be made to keep her up for at least two hours, walking her a short distance every ten or twenty minutes during this time.

I can sincerely recommend this as a certain preventive of this condition, a condition which is very unsatisfactory to treat. Once obstetrical paralysis is fully devoleped, a guarded prognosis must always be given.

Some of these cases lie around in this condition for three or four weeks and then die. Others lie around just as long and recover. Sometimes the condition terminates in complete recovery within three or four days and I have known them to terminate fatally also, in an equally short period. Recovery is the rule, but the duration of the period of recumbency is so varied and so indefinite that statements on the part of the veterinarian forecasting the termination must be given guardedly.

Probably the best and most prompt effect in treating cases which have been allowed to develop this condition (I say allowed to develop it because it can certainly be prevented) is obtained by frequent vaginal douching with hot water containing just a trace of fluid extract of belladonna. This in conjunction with strychnine or nux vomica administered internally is rational and quite satisfactory. 


\section{Protracted or Prolonged Colics.}

Nearly all practitioners of veterinary medicine have had cases of abdominal pain which were difficult to terminate.

Frequently a case presents almost typical signs of acute indigestion, or possibly of a simple spasmodic colic, or of mild impaction. The treatment, which is usual in such cases, is given and while, possibly, some temporary improvement is shown the case slowly develops certain symptoms which are atypical and "hang fire."

We continue our treatment from stomach tube to eserine and everything that could possibly be indicated. If we have profited by former experience with cases of this kind, we go slowly as soon as we recognize what we have; we begin a sort of "watchful waiting" process; and the horse finally recovers. Before we had profited by experience, with these cases, we kept up our treatment continuously, we did too much, and we lost the patient.

It is my opinion that in all of these cases a localized enteritis or gastritis has developed, either from excessive pressure on a small area from gas or from coprostasis. This area may be very small, possibly no more than a few inches square, as I have noted repeatedly on post mortem examination in cases which died from typical attacks of acute indigestion.

If the veterinarian desists from administering further heroic treatment as soon as he realizes that he has a case of this kind in hand, the process stops and recovery supervenes. If, on the other hand, he does 
not recognize the condition and continues with his active medicaments, he helps to bring about extension of the inflamed area, causing it to assume such proportions that death must supervene.

I have worked out a prescription for such cases as these which has given me very much satisfaction and I can fearlessly recommend it. This is it:

$\mathbf{R}$

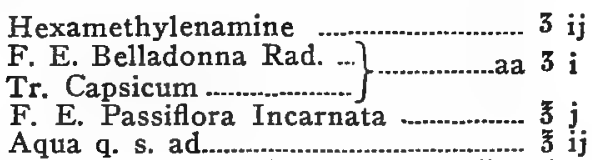

The hexamethylenamine is first dissolved in the water and then mixed with the other ingredients. This is given at one dose in capsules or with syringe and a similar dose is given every two hours for three or four doses, if necessary.

This treatment is intended solely to relieve inflammation and the pain produced thereby, and it gives fine results in the cases for which it is recommended.

A very important point in the after-care of cases of this kind lies in absolute abstinence from all food for at least twenty-four hours after all signs of pain have lefit. Nothing but water should be allowed.

If it should occur that the veterinarian has erred in diagnosis by failing to recognize a volvulus or an invagination, he is doing no harm. Even in such cases, whether a correct diagnosis is made or not, the horse has a better chance for his life with the foregoing treatment, by a wide margin, than he would have if the usual colic, acute indigestion or impaction treatments were kept up. 


\section{Intravenous Medication.}

It is not my purpose to take up the entire subject of intravenous medication, nor to give the reader any new thought or method along this line. I simply wish to register a warning note against the indiscriminate use of medicaments by direct instillation into the blood stream.

In this, the average graduate veterinarian allows his best judgment and his fundamental knowledge of the rudiments of his profession to fail him. In this, the indiscriminate use of intravenous medication, he infringes most unpardonably on the kindness of nature and commits his worst offences on the side of quackery. Were this all it would not yet be so serious. It is the harmful and uncertain effects which such treatment has on the future well-being of the patient which makes this subject really worthy of attention.

It is only rarely that these harmful effects are noted immediately and seldom if ever are they traced to their causative factor when they ultimately make their appearance.

I remember only one instance where I noted an untoward effect within a short time. It exhibited itself as a blindness and facial paralysis within twentyfour hours.

Many are the conditions, of varied pathological significance, which may follow at long intervals upon the intravenous injection of intolerable or, improperly administered, tolerable medicaments. Chief among these are embolism with its multiplicity of local phe- 
nomena, especially lameness and various demonstrations of trophic nerve disturbance.

In choosing agents for exhibition by the blood stream, we should respect the delicacy of the tissue with which the agent comes into such intimate contact. We should remember our physiology and our histology enough so that we do not ignore the fact that of all animal tissue, blood will least bear contact or handling in any form. We should not forget, especially, the microscopically delicate net-works of capillaries and terminal vessels through which it must pass unhindered. We should remember how delicate is the physiologic chemistry of the blood and how little it takes to disturb the equilibrium of this vital formula. All too frequently, the veterinarian forgets his early teaching on this subject and many times the ultimate harm done the patient heavily outweighs the good.

The veterinarian can gain much by keeping track of the cases in which he uses intravenous injections. In most cases after varied intervals, the patient develops some form of lameness, some apparent functional disturbance, or some puzzling atrophy, which is hard to handle. Lameness such as follows this procedure is usually obscure, difficult of diagnosis and resistant to treatment.

If we, as veterinarians, would bear in mind that physicians, who have every facility to make intravenous medication ideal, consider it a measure to be used only in dire extremes, we would not go about it so carelessly and promiscuously. 


\section{Subspinal Anesthesia--Abdominal Operations.}

This anesthesia is obtained by injecting mild, nontoxic solutions of local anesthetics, of which stovaine is the best, into the peritoneal cavity. Immediately after the solution has been injected the dog is placed in the dorsal recumbent position and held in this position until the anesthesia is established, requiring usually about fifteen minutes.

The anesthesia obtained in this manner affects the entire abdominal viscera and is so complete as to permit of free handling or incising or dissection of the parts. The skin remains sensitive and the animal is wide awake. The failure of the skin anesthesia can be overcome by injecting a little of the solution subcutaneously at the seat of incision. Anesthesia by this method prevails for several hours if stovaine is used and there are no bad after-effects.

In occasional cases an obturator paralysis is temporarily established, lasting for three or four hours. This is evidenced by a straddling or sprawling gait behind when the dog is placed on his feet after the operation. It seems that he finds it impossible to abduct the pelvic limbs. This paralysis lasts only so long as the anesthetic is active, from one to four hours. 
The advantages of this method of anesthetizing are many. No attention need be given the patient after making the injection, therefore no assistant is required for this part of the operation. No shock follows even the most prolonged and extensive operative interference under this anesthesia; there is no post-operative nausea and the animal requires no watching as is the case when it is reviving from profound chloroform anesthesia.

The technic is simple, the point of greatest importance being cleanliness.

For a dog weighing twenty-five pounds one ounce of a one per cent solution of stovaine is sufficient. The solution should be sterile and used at blood heat, a little more than luke warm. Half an ounce is injected into the peritoneal cavity on each side of the median line, making the needle enter just in front of the brim of the pelvis near the fold in the flank. The abdominal muscles are most favorable for puncture at that point. A very fine needle and ordinary hypodermic syringe can be used. A little practice makes it possible to determine without much difficulty when the needle enters free in the abdominal cavity. The solution must not enter an intestine or other organ but must be placed within the peritoneal cavity.

As soon as the injection is completed the dog is turned flat on his back and forced to remain in this position by hobbles or other means. In fifteen minutes the operating can begin.

If it is desired to anesthetize the skin only for the primary incision, an ethyl chloride spray may be used. 
If it is desired to continue the skin anesthesia until the end of the operation, a few drops of the stovaine solution injected along the line of incision will give this result.

In case obturator paralysis supervenes, the dog is kept quiet for several hours after operation. No treatment is necessary, as it always passes off in a few hours.

This method of anesthetizing, although used by some veterinarians for a number of years, is in direct accord with the most recent progress along surgical lines, namely anoci-association or the prevention of surgical shock. Professors Crile and Lower have just completed a valuable monograph on anoci-association which is now in the hands of the publishers. (W. B. Saunders Publishing Company, Philadelphia.)

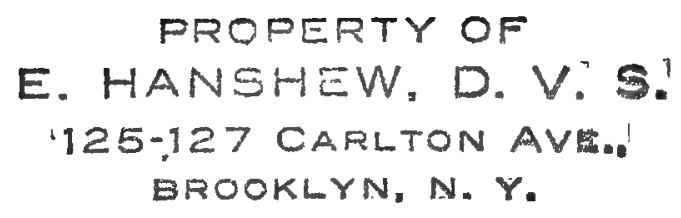





\section{The Treatment of Tetanus with Passiflora Incarnata.}

Tetanus is one of the several conditions which affect veterinary patients for which there is as yet no generally accepted treatment. Antitetanic serum has fully established its worth as a sure prophylactic but there is much doubt as to its real value when the symptoms of the disease are once in evidence.

The accepted and, at the present time, the method most in use when serum is used in the treatment of this condition, is the injection of only one or two immense doses in the outset of the treatment. It is quite generally believed that after this the further administration of serum is of no benefit. Occasionally cases are reported in which a rapid recovery apparently follows the injection of antitetanic serum. It is doubtful whether these cases are cases of genuine tetanus. Real tetanus due to infection by Nicolaier's bacillus is always a disease which persists for a long time. A recovery in four weeks is considered rapid; usually it requires six or eight weeks.

In the treatment of this disease, we must rely almost wholly upon agents which will reduce the nervous excitability, and the entire treatment of tetanus today is symptomatic, with the exception of the local treatment of the wound, when it can be found.

Usually the attending veterinarian is satisfied with the condition of his patient in this disease, if he can keep his patient free from spasmodic muscular contractions, trisms especially affecting the masseters and 
cervical region. Since 1905 I have been using the fluid extract of Passiflora incarnata for tetanus spasms.

The one great advantage that this drug has in this condition lies in the fact that it can be given indefinitely in the same dosage without the effect becoming less. In other words, tolerance for the action of the drug does not develop; an ounce gives the same effect at the end of two weeks' continuous treatment as it does from the first dose.

The action of this drug seems to be selective in this disease. It can not be described as a hypnotic nor as a narcotic action. It seems to have a clear sedative effect, restricting its power to the abatement of the nerve irritability. The patient shows only this effect; no evidence of drowsiness or inertia.

My method is to arrange matters so that the horse will be given a full ounce of the drug every three hours, day and night, during the first forty-eight hours. By this time the full physiologic effect of the drug is obtained. This effect may then be maintained indefinitely by giving an ounce every three or four hours during the day, beginning early in the morning and stopping late at night. This course should be kept up day after day until there is such improvement that only an occasional dose need be given during each day. The drug may be given undiluted with a dose syringe.

Usually the horse is fairly relaxed from this treatment within a day or two, and most of my cases are almost fat by the time they recover. With other forms of treatment, it has been impossible for me to terminate a well marked case of tetanus with the horse in good flesh; more often than not they were wasted to only a shell of their former condition. 


\section{Contagious Abortion in Cattle.}

Remarks on this subject will be confined to the use of methylene blue as a treatment.

As the methylene blue treatment is a comparatively recent addition to our weapons against contagious abortion, my experience with the treatment covers a short period of time, about one year. Elsewhere in this work I have advocated only thoroughly tried out treatments, treatments that $I$, have employed over several years and in a number of cases sufficiently large to speak with authority concerning them. It is therefore with some hesitation that I recommend this comparatively little tried treatment.

During this period I had an opportunity to give the treatment a fair test in three herds in which the disease had a strong foot-hold, having existed continuously in one of the herds for over five years, during which time every known treatment had been used and had failed to check it. Under the methylene blue treatment this herd has apparently been absolutely purged of the trouble, all cows going to full term with live calves last season and not a single abortion occuring since the treatment was given. In the second herd, as high as three cows aborted in one week and the infection seemed to be especially virulent. Under methylene blue treatment, the abortions promptly stopped and apparently the herd is clean. 
The third herd had been infected for about two years, the disease was well established and apparently beyond control. In this herd also no further abortions have occured since the treatment was given.

This experience is very limited on which to base an opinion, but considering the conditions and the uniformity of results, from these three reports, I must of necessity say that my results with the treatment have been one-hundred per cent perfect. Some of my colleagues have not found the treatment so satisfactory, but I find on looking into the matter that my method of using the treatment has differed much from theirs.

Comparing my method with that of others, I would call mine an "intensive" treatment. I use larger doses than others use and give them more frequently. My system consists of giving the methylene blue in halfounce doses, once daily for six days. I then allow a week to pass without treatment and then give onehalf ounce every other day until another six doses have been given. This completes the treatment.

I give the methylene blue in capsules with a balling gun, half an ounce to each cow as described above. If there is a bull in the herd, he gets the same treatment. Here is another place where my method differs from others; I treat the bull the same as the cows. Possibly the differences in my method are the points that have so far made the treatment one-hundred per cent perfect for me. I have been using doses about ten or more times larger than were at first recommended by the discoverers of the treatment. I have 
seen absolutely no bad effects at all from such dosage.

During the week which elapses between the two treatments, I see to it that the entire cow stable and cow yard are thoroughly renovated. The stable is then thoroughly disinfected and at once white-washed. If the cow-yard contains an old manure pile, it is to be taken out and used on land where the cattle are not likely to graze at any time. I allow no outside cows to be bred to the herd bull and new additions to the herd are given the same treatment as the infected animals whether they are known to have the disease or not.

My limited experience with this treatment leads me to believe that we have in methylene blue almost a specific against this disease. Further experience may enable us to so perfect the method of using this treatment to an extent that it will be quite uniformly successful.

The interesting point with this treatment appears in the fact that in the three herds in which I used it the disease seemed to stop immediately, no abortions occuring after the treatment was once under way. In one herd a cow aborted on the day treatment was begun, but there were no abortions later. 



\section{Choke in the Ox.}

Choke in cattle differs very much from the same condition in horses in so far as treatment is concerned and also as regards the nature of the agents producing. the choke.

In the cow probably most chokes are from solid bodies, such as portions of vegetables and other solid food. These block the esophagus chiefly because their dimensions exceed its calibre.

Choke in cows is usually a more threatening ailment than it is in horses; the symptoms are more acute. In addition, tympanites is a common complication. The treatment of choke in cattle is almost wholly mechanical or surgical.

When the offending body is in the cervical portion of the esophagus, it can usually be plainly felt by palpating with the fingers. Sometimes the body is so large that it produces a bulge in the esophagus which can be plainly seen.

If the veterinarian's examination locates the body in the region of the pharynx or just below it, an effort should be made to extract it through the mouth with the hand while an attendant attempts to gently push the body closer to the pharynx. When this attempt fails, it is advisable to leave the patient alone for a number of hours in a stall where only water is to be had. In many cases where the offending body is in the upper third of the esophagus, the object is ex- 
pelled spontaneously in a few hours. I reported a case in the Amerlcan Journal of Veterinary Medicine (April, 1914), which illustrates such an occurence.

In the horse, the mass of food causing the choke can pass only towards the stomach. In the cow, recovery, many times, follows, from regurgitation of the obstruction. This is a point which must not be overlooked in treating cattle for choke.

If, in a given case, the obstruction has not been dislodged after eight or ten hours of "watchful waiting" a probang may be used cautiously. If the object is not quite easily moved by the probang, if it resists moderate repulsion, this means of treatment should be discontinued at once and esophagotomy performed. This applies, of course, only to cases in which the object is in the cervical portion of the esophagus. In cases of thoracic choke the probang treatment must be patiently persisted in until something is accomplished.

Esophagotomy in cattle is a simple proceeding attended by fairly uniform success. Even when performed under trying handicaps, I have seen excellent results follow this operation. The seat of operation is directly upon the object. The hair is shaved, or at least clipped, for a considerably larger area than the incision would require and the skin ordinarily disinfected with tincture of iodine.

An incision is made directly down onto the object and somewhat longer through the muscle. When the esophagus is reached, only a very short incision is first made into it and an endeavor is then made to re- 
move the objection, if a piece of vegetable, in sections with forceps.

If this cannot be accomplished after a few trials, the incision into the esophagus is enlarged and the object removed en masse with forceps or with the fingers. Usually it requires a considerable amount of force to extract the object and one can readily appreciate why it is so difficult to dislodge these objects by means of the probang.

When the body has been removed the surgeon usually proceeds along lines which previous experience, has taught him. In my early experience, I took pains in approximating the edges of the esophageal incision. Today, I do not suture the esophagus at all. It has been my experience that healing comes just as quickly and just as thoroughly without sutures of any kind excepting a continuous suture through the muscle and skin. With the best judgment in suturing the esophagus, some food always comes through the incision for a week or ten days.

After the muscle has been closed by suture, the after treatment is confined to daily application of an antiseptic solution. This should be applied with a syringe held a considerable distance from the wound so that the solution merely bathes the external surface; possibly a small amount of it entering interstices between the suture.

The cow should be fed nothing but very thin slops and water as long as any particles of food escape through the wound, usually for about ten days or two weeks, 
My results from this operation have been very satisfactory and in no case did a permanent esophageal fistula become established. While almost every rule of legitimate surgery is violated in this method, it gives good ultimate results, and just as promptly, as are obtained when every means is taken to perform a classical operation. 


\section{Paraplegia as a Sequel of Canine Distemper.}

This condition, following on severe and prolonged attacks of distemper is seen frequently. Its treatment embraces a great variety of unsuccessful therapeutics and, as a rule, veterinarians have been in the habit of ordering the destruction of the dog when this sequel supervened on a case of distemper.

Our experience with this affection was very discouraging up until the year of 1909, when a series of studies and experiments, resulted in the elaboration of a very satisfactory treatment.

Our first success with this treatment was reported in the American Veterinary Review in that year by my brother, a student at the time, and myself.

Our theory of this condition as formulated at that time was that a sclerotic tendency is present in the spinal cord, varying in degree with the severity of the symptoms of paresis. Whether the theory is correct or not is immaterial; the treatment which we based upon this theory was successful and to a certain extent that proves the theory.

On this hypothesis, we decided that if we could place a bland and at the same time fibrolytic agent in more or less intimate contact with the spinal cord, we could correct the abnormality. 
On these lines, our selection fell on thiosinamine, whose action on sclerotic processes is selective. It can be obtained in sterile, graduated ampules, under the trade name of "Fibrolysin," and it is in this form that we use it. In our early work along this line, we deemed it essential that the drug be deposited subdurally. Later we found that the same results could be obtained by epi-dural injections.

The modus operandi is as follows, under chloroform :

An area of an inch square over the alto-axoid space is shaved and thoroughly cleaned. With a very fine hypodermic needle a puncture is made straight down onto the cord, passing the needle slowly in until a sudden freedom from resistance gives evidence that the point has entered the neural canal. This is easy to recognize after a very little practice. The head is to be sharply flexed on the sternum while the entrance is made and until the needle is withdrawn.

When the characteristic sensation of absence of resistance is felt, the hypodermic syringe, containing the fibrolysin at body temperature, is attached to the needle and the contents very slowly injected. The needle is withdrawn quickly and the seat of puncture is then painted with tincture of iodine. This completes the treatment. The dose is one cubic centimeter of fibrolysin to twenty-five pounds of live weight.

Within a few hours after the injection, the animal exhibits typical symptoms of brain trauma, delirium and partial coma. This passes off in from eight to 
twelve hours and almost immediate improvement is shown as regards the general condition, paraplegia and inco-ordination. Even during the first twenty-four hours following the disappearance of the brain symptoms the animal has better control of his movements. Symptoms of chorea of certain muscle groups (which may have been present) are less frequent and less severe and co-ordination is again becoming established in the posterior parts. Improvement progresses rapidly day by day, until at the end of two weeks, the animal has almost normal control.

Tonics and warm quarters help to hasten final and complete recovery. No attempt should be made to carry out this treatment except under profound anesthesia.

In our early work, we used morphine narcosis; this is contra-indicated in view of the brain symptoms which follow the injection and, besides, the anesthesia is not complete and therefore dangerous in this procedure. A slight jerk when the point of the needle is in situ could do irreparable damage. 



\section{Treatment of Pneumonia with Sparteine Sulphate.}

In the American Journal of Surgery (July, 1912), there appeared an article on the use of sparteine sulphate in human medicine. The author states in the article that it is his opinion that poor results from the use of this drug are due to improper dosage. $\mathrm{He}$ recommends doses nearly ten times larger than are usually considered proper.

I had given sparteine sulphate a trial in pneumonia as far back as 1905 and had discarded it for more active agents. Upon reading the article above referred to I decided to give the drug another chance and began to use it again, but in much larger doses than previously. Instead of using only a two or three-grain dose as in our first experience with the drug, I began this time to make the average dose, twenty grains. And I was very agreeably surprised at the marked benefit derived, especially in pneumonia in cattle.

The salt is very soluble and can be made up in solution with water readily. I make a solution of such strength that an ounce represents twenty grains of the drug, and direct that an ounce be given every three or four hours. During the past winter, I treated a number of cases of pneumonia successfully with this alone. 
Sparteine is a safe heart tonic for this disease because, while it increases the force of the heart action, it does not raise blood pressure. I believe that this is its chief superiority over other drugs in the treatment of this disease.

Besides its value as a heart tonic it possesses diuretic properties and it increases the appetite. In the last respect it acts as a bitter tonic and its effect is quite the opposite of that of digitalis.

Sparteine sulphate can also be administered hypodermatically when heart failure is imminent, its effect commencing within ten or fifteen minutes, becoming fully established in about an hour and persisting from three to six hours.

The best system for its application in a case of pneumonia is to give it in solution by the mouth every three or four hours during the day. Results are all that can be desired. Often the attack seems to terminate within four or five days, the temperature approaching normal and the lungs apparently clearing up.

I would call attention again to the fact that this drug is the ideal heart tonic for this disease because it increases the force of the heart action without raising blood pressure. Given every three or four hours, twenty grains should not be exceeded as a dose; if larger doses are given, say twenty-five to thirty grains, doses every five or six hours suffice. On the average twenty grains every three or four hours are better than the larger dose at longer intervals. 


\section{Creosote for Intestinal lnfections.}

Creosote is a valuable, but much neglected agent in veterinary medicine. Probably the chief reason for this lies in the fact that, because of its disagreeable odor, our patients must either be drenched with it, or it must be administered in capsules. Most animals refuse to eat it on the feed.

While useful for a great variety of diseases and pathologic conditions, it is in infectious conditions of the intestinal tract that creosote gives its best performance. In various forms of dysentery and in secondary intestinal catarrh, it may be depended upon without question.

For internal administration only the beechwood creosote should be used. The average dose for horses can be put at fifteen minims, for cattle twenty. It should always be combined with a bland' oil such as linseed, cotton-seed or castor oil.

A good capsule for acute scours is the following:

R

Creosoti (Beechwood)......................... xv

Tr. Capsici

O1. Cajuput

O1. Ricini, q. s. ad

5 i

M. et fiat capsula.

3 iv

Sig.-Give at one dose for scours. This may be repeated in an hour if necessary.

In affections of the intestinal tract, in which the feces have a disagreeable odor, creosote can be used 
to advantage, a few doses overcoming all objectionable odor. When used in conditions which require the drug to be given three or four times daily the dose should not exceed seven or eight minims. In doses of fifteen minims repeated two or three times at regular intervals a vermicidal effect will be obtained which is quite thorough. 


\section{Retained Secundines in Cows.}

Retention of the after-birth in cows is one of the most common abnormalities associated with pregnancy. This is especially true in localities where contagious abortion prevails.

From time to time there appear in our journals reports of new, and sometimes long-forgotten forms of treatment and methods of removing after-births. When all has been thoroughly gone over and tried out in every day practice it can not be denied that the only safe, complete and satisfactory removal of a retained after-birth is by manual extraction. The longer we are in practice, the more surely we become convinced of this.

The greatest discrepancy in agreement among veterinarians lies in the point relating to the time which should elapse after the expulsion of the fetus béfore extraction of a retained after-birth should be attempted. The period advocated varies from one to three days, with some advantages on each side and disadvantages on all.

From the standpoint of science, from the standpoint of surgery and from the standpoint of milk hygiene twenty-four hours is the limit of time to elapse between the birth of the calf and the removal of the after-birth. At this time the os is still wide open so that every cotyledon can be reached and freed from the encircling envelope. Also at the end of twentyfour hours, practically no sign of tissue degeneration is yet evident. 
The "third-day" advocates present their side with the argument that it is practically impossible to remove the afterbirth from some of the cotyledons before the third day. Even if this were a fact, which I doubt, it would be better to leave attached a few small shreds of clean tissue which will probably not undergo degeneration at all if the uterus is carefully swabbed, than to allow the entire mass to approach a state of foul decomposition, which is always the condition presented if three days elapse. By the third day the placental portion of the secundines has always degenerated and the uterus is a sticky, slimy and far from pleasant smelling organ.

I am thoroughly aware of the fact that from the standpoint of manual labor, the third day is the day of choice. Gentle, steady traction with appropriate torsion brings out the envelopes en toto. But the decomposed, semi-liquid placental debris and other discharges remain. The os has become closed to such an extent that only two or three fingers can enter and it is practically impossible to thoroughly cleanse the organ. From every professional standpoint, twentyfour hours is a sufficient length of time to wait before resorting to manual removal.

This has been my rule over a period of more than ten years and out of several hundred cases, I have yet to lose the first one. On the other hand, I have had deaths from waiting too long, sometimes three days, and unsatisfactory terminations even after two days.

After completing the removal, my method is to swab out the uterus with solid fists full of absorbent 
cotton after pumping in a mild antiseptic solution. By this means a case of this kind can invariably be left in a clean, comfortable state. No straining is seen if the swabbing is done thoroughly and there is no dribbling of discharge for days afterward as occurs usually without swabbing.

In neglected cases which show signs of puerperal infection much good comes from the use of polyvalent bacterins. In fact, it is good policy and evidences sound judgment, to administer a full dose of bacterins in every case of retained after-birth.

\section{Latent, Imbedded Foreign Bodies.}

Space is devoted to this subject only for the purpose of emphasizing the diagnosis of such conditions as result from foreign bodies remaining deeply imbedded in tissue.

Whenever a tumefied area in the soft tissues continues to discharge indefinitely, healing up for a short time and then breaking out again, it is safe to assume that a foreign body of some sort is present. Radical surgical intervention is then indicated and free, bold incision into the enlargement will usually reveal the causative agent, often a small piece of wood.

These conditions nearly always come in the parts where heavy muscles predominate. Allowance must be made for thecal abscesses in regions where bursae exist, and it must also be remembered that in the locations of the various groups of lymphatic glands a suppurative condition may occur resembling one due to a 
foreign body. However, in the case of foreign bodies the discharge is less of the nature of pus and is sanguinolent in character, almost a "bloody water," as the client usually expresses it. 


\section{Botryomycosis.}

This is a condition which is very troublesome in the southern half of the United States. It occurs to a certain extent in the north also but not so extensively nor is it so virulent as it is in the south, where it has assumed such proportions and presents such grave problems that I believe it is only a question of time when it will require rigid quarantine regulations for its control and eradication.

From an experience with this condition in Texas, Oklahoma, Arkansas, New Mexico and Old Mexico, covering a period of nearly six years, I am convinced that we have in veterinary medicine no other single infection which can appear in as great a variety of forms, which attacks as great a variety of tissues and which presents such tenacity of life.

Veterinarians in the south have observed botryomycotic infection of nearly every organ in the body. In certain localities, the most trivial injuries, such as abrasions from interfering, chafes from the harness and other minor hurts develop into most troublesome sores as a result of this infection. 'The slightest wound should not be neglected in these regions.

I have seen valuable stallions made worthless for breeding purposes as a result of botryomycotic infection of the sheath and penis, the organ developing on the glands a cauliflower-like growth the size of a 
cocoanut. No tissue (with the possible exception of bone) is resistant to the infection.

A very common form occurs in the lower corner of the eyelids with the formation of great quantities of the typical granules in and around the lacrymal sack and at times extending down the lacrymal duct. In this location the infection is usually handled successfully by careful and thorough removal of the granules with a very small eye curette and the subsequent treatment consisting of daily application of a mild ointment of yellow oxide of mercury. Two or three curettements may be necessary.

In all other parts of the body this disease is very resistant to treatment. The tendency is towards the rapid and extensive formation of fibrous tissue, which in advanced cases becomes almost cartilaginous in consistency. Whether this is the direct result of the infection or whether it is an effort on the part of the tissues to wall off the invading organism I do not know. At any rate, this development takes place very rapidly and causes the formation of a tumor in a short time. The surface of this tumor usually remains bare and raw and the characteristic granules or small "gravels" can be plainly seen. If the tumor is incised they will be seen to extend in every direction and frequently some of these granules are found in apparently healthy tissue entirely outside the borders of the tumor.

The surface of the tumor is kept raw by almost constant rubbing on the part of the horse. Itching seems to be all but intolerable and if the lesion is in a loca- 
tion which can be reached with the teeth the animal is constantly gnawing it.

The infection is undoubtedly carried by flies. I once noted on the postmortem examination of a horse that had died as the result of prolonged colic, a botryomycotic enlargement of all the mesenteric glands. The glands had become enlarged to the size of hen eggs and contained throughout the hypertrophied texture numerous characteristic granules.

During cool weather the symptoms partially subside and if the winter is cold enough and is not too short, some cases apparently heal over nicely. As soon as warm weather returns however, the infection becomes active again and the disease progresses rapidly. From this the disease has probably received the common name of "summer sore." Also for this reason, undoubtedly, the north has but little trouble with this infection, the winters being too severe and too long for the favorable growth of the infective organism.

To the practitioner who has had little or no experience with this infection it would appear a very simple matter to excise the entire growth. Those veterinarians who know this condition can testify to the futility of this procedure. Though the dissection be ever so thorough, a cure rarely follows. This is no doubt due to the presence of some of the botryomyces in tissue not involved in the tumor and would be a point in favor of the theory that the formation of fibrous tissue is due to an effort on the part of the system to wall 
off the infection and not to the direct action of the botryomyces.

Another obstacle to surgical removal of these tumors lies in the fact that just as often as not, they are located in and involve parts of the anatomy where extensive dissection is out of the question. For these reasons surgical removal is not practical, although, theoretically, it may be the ideal procedure.

A discussion of the various medical and chemical agents which have been resorted to in the treatment of this condition would make an endless volume and would lead to no satisfaction.

There is a fine field for research in this disease and a good, reliable treatment is yet to be worked out. A better understanding of the condition from a standpoint of pathology and bacteriology is essential.

In 1907, Dr. Frank Thatcher, then city bacteriologist of El Paso, Texas, isolated a foreign bacillus from lesions of botryomycosis. The bacillus was anaërobic and resembled tubercle bacilli morphologically. A bacterin was made and used with some success, after which the investigations were dropped.

The best results in my cases were obtained with a "cancer-paste" which is quite generally used by veterinarians in the south. The active principle in this paste is cobalt and it is usually made as follows:

$\mathrm{R}$

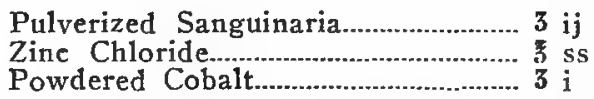

This is made into a paste with water, requiring much grinding in a mortar before it becomes smooth. 
Some veterinarians add cocaine to make it painless when applied.

When the paste is prepared it is spread on a thin layer of cotton, the raw surface of the tumor is swabbed thoroughly dry with absorbent cotton, and the thin layer of cotton containing the paste is then snugly pressed onto the surface. It dries and adheres firmly in a few hours, during which time the horse must be prevented from biting or rubbing the part. When the paste once becomes fixed on the tumor all itching seems to stop at once and in a few days the tumor decreases considerably in size and assumes an appearance of general improvement.

After the lapse of ten days or two weeks the entire mass drops out, leaving a healthy, granulating cavity which is then treated with astringent lotions until healing is complete. This treatment gives fairly uniform, but, by no means universally, successful results.

Every observation of this condition points to best results with agents of alkaline re-action. Acids are generally not favorably received in this affection.

This disease is of such a character and is so general throughout the south that it is a worthy subject for investigation by our research men. Much appreciation awaits him who elaborates a uniformly successful treatment for this disease. 


\section{Chronic Edema of the Hind Extrem- ities-Stocking.}

Persistent stocking in the hind legs from the hock down is a somewhat common condition. Close observation will disclose the fact that geldings are most often affected.

Stocking affects mares as well in conjunction with various skin diseases, such as scratches for instance. It is chiefly in geldings that stocking occurs as a clinical entity without apparent lesions of any kind on the extremities involved.

In most of these cases either an excessive amount of scar tissue resulting from castration is present or a scirrhus cord is present or beginning to form.

If the veterinarian will carefully examine the region about the scrotal fold in geldings of any age whose hind extermities "stock" habitually, he will invariably discover one of the above mentioned conditions. If it is merely a case of a pad of dense scar tissue with surrounding adhesions, iodide of potash will give excellent results. Even in some small scirrhus cords, prolonged administration of iodide of potassium will terminate the trouble. In scirrhus cords of larger dimensions, surgical removal is the only recourse. However, in all cases a good course of potassium iodide should be tried first as frequently it gives results when least expected. 


\section{Pulmonary Emphysema-"Heaves."}

Common as this condition is in veterinary patients it is doubtful whether there is a condition which is treated in a more careless and empirical manner.

In the first place it is customary with most practitioners to treat all dyspnea of a chronic nature referrable to the thoracic cavity as pulmonary emphysema. It is chiefly for this reason that the various treatments in vogue for the relief of this condition are so uncertain in results.

Unless the patient in question is under observation for a long time or, unless an intelligent history of the case can be obtained, pulmonary emphysema can be diagnosed only by careful auscultation and percussion; a proceeding to which the general practitioner resorts but rarely. A diagnosis arrived at by mere inspection of the inspiratory movements and expiratory spasm of the abdominal muscles is of no value from a standpoint of treatment.

True pulmonary emphysema is, of course, incurable. Intelligent treatment, however, can do much towards enhancing the value of the patient as a serviceable animal. More than this, our knowledge of the pathology of the disease forbids us to expect. And in this lies the point of value in careful examination.

Knowing that in a case of true pulmonary emphysema we can give our client little or no encouragement of cure, it is little short of criminal from a professional standpoint to err, through fault of a superficial exam- 
ination, to the extent of confounding a possibly cureable condition with this one.

In pulmonary emphysema such structural changes have taken place in the lung that it would be evidence of inferior mental calibre to attempt their repair by medicinal means. Likewise, surgical interference is out of the question, although an operation of section of ribs has been used for relief of the dyspnea induced by pulmonary emphysema.

In the treatment of the dyspnea from pulmonary emphysema, no set rule should be adhered to. Although the pathology is identical in all cases the response to various forms of treatment varies greatly. Many cases can be much improved with ordinary antiacid treatment, such as bicarbonate of sodium, sodium borate and similar salts. In other cases arsenic works wonders.

A valuable drug in this disease which has not come much into use among veterinarians in America, is grindelia. The fluid extract is the most convenient form and the effect is usually very gratifying.

It is always well to begin with a small dose which should be gradually increased until the desired effect is obtained.

Arecoline has been recommended as a diagnostic agent for pulmonary emphysema, but is unreliable because it has the same effect in cases of functional neurosis such as asthma and bronchio-spasm, that it has on pulmonary emphysema.

It is doubtful whether definite diagnosis is possible by any other means than auscultation and percussion. 


\section{Neglected Medicinal Agents in Veterinary Medicine.}

Compound Tincture of Benzoln : (Friars Balsam). Compound tincture of benzoin is of much value in treating various forms of stomatitis and such conditions as ulcers on the oral and nasal mucous membranes, alveolar abscess, gingivitis and lacerations of the tongue. For these affections it is applied occasionally during the day full strength with a cotton swab or camel-hair brush.

Shaken up with equal parts of glycerine the compound tincture of benzoin is a good application for cracked teats. It should be applied after milking.

It finds its best field, however, in affections of the mucous membranes, especially in the mouth.

Oil of Cajuput:

In parasitic skin diseases we can use nothing better than this volatile oil.

In certain forms of intestinal fermentation it is a good remedy, for instance in such as result from the ingestion of green food.

As a fly repellant on the surface of wounds it is excellent when suspended in heavier oils. In liniments for rheumatic pains, it also has a place.

HeXamethylenAMINE.

This drug can be absolutely depended upon to prevent infectious cerebro-spinal meningitis. It is quite 
soluble and in solution almost tasteless so that it can be given in the drinking water. For horses, two drams, three times daily in drinking water is a sure preventive of the above disease.

It is also very useful in cystitis, urethritis and arthritis, besides possessing valuable properties as an intestinal antiseptic. It has been held that it must be given in conjunction with an acid. Clinically this has not been found necessary.

Passiflora Incarnata.

The fluid extract of this drug is of real worth in veterinary practice. In all conditions other than surgical operations, in which it is desirable to relieve pain, passiflora stands first in the list of drugs.

Its action is more one of calm sedation than of hypnosis or narcosis and this effect may be kept up indefinitely by proper dosage without any bad aftereffects whatever.

An ounce dose can be given every hour if necessary until the physiological effect is produced; then its administration less often will maintain this effect. In conditions in which opium or morphine are contra-indicated, passiflora may be used effectually.

Mercurials:

Of these the most serviceable in veterinary practice is the proto-iodide. It has real value in general infections and glandular diseases in from two to three grain doses, especially when chronic.

In the secondary pustular and suppurative conditions of canine distemper doses of one-sixteenth grain work wonders. 
In the enlargement of the parotid gland frequently seen after quinzy this drug gives good results.

The hardness remaining in udders after mastitis yields to a course of treatment within a few weeks' time.

Potassium Dichromate:

Besides its specific action in infectious entero-hepatitis in fowls, this salt should not be forgotten in chronic affections of the upper air passages. In two to four grain doses in solution it can be depended upon to stop coughs and catarrh which follow laryngitis, pharyngitis and influenza.

Locally, in five per cent watery solution, it hastens the disappearance of swelling in lymphangitis and local glandular swellings, if applied with a brush twice daily. In powder it is a good packing for thrush, better than calomel and much cheaper.

Stovaine.

Of all local anesthetics stovaine takes the preference in veterinary practice. It is practically non-toxic for our patients and immense quantities can be used in solution without producing the untoward effects of cocaine.

The anesthesia from stovaine lasts about three hours and is just as complete as cocaine anesthesia. Stovaine is cheaper than cocaine and solutions of it do not decompose as quickly as cocaine solutions.

Care must be taken to keep it from contamination with alkalies. Even a trace of alkali makes it inert.

Chromium Trioxide:

This is an ideal agent in two per cent solutions for 
use in abscess cavities. The same strength solution gives fine results in the treatment of warts if applied with a brush once or twice a day.

Cotton saturated with a five to ten per cent solution makes a good swab for foul smelling sores, ulcers or wounds.

For thrush, cotton saturated with a ten per cent solution makes a good packing. 


\section{Stock Colic Mixtures.*}

All, I think, will acknowledge that colic in its generic sense cannot be properly nor scientifically treated by stock mixtures which of necessity must be of the "shot-gun" variety. However, we are forced to suply some of our clients with a "colic remedy" for various and obvious reasons, one of which is to prevent them from using quack nostrums and another is to save ourselves from being called out at night.

This being so, study the question closely and omit drugs like opium, morphine, cannabis indica and hysocyamus, which are non-curative, and will mask the symptoms should the case later demand your personal attention. In addition, they will retard the effects of the quick-acting cathartics, should they be given.

Anodynes and antispasmodics which may be substituted for the above and which do not have their objectionablle features are belladonna, stramonium, acetanilid and oil of turpentine.

It is best, on stock-mixture labels, to advise that not more than two doses be given, and that upon the failure of the second dose the doctor be called. This limitation of the number of doses is imperative if they contain any of the poisonous drugs.

\footnotetext{
-This and the following article were not included in Dr. Steffen': manugcript. This discussion is excerpted from an article on the "Medicinal Treatment of Colics," by E. L. Quitman, published in "Collo and Their Treatment" by the Ameriean Journal of Veterinary Medicine, Dvanaton, Illinois.
} 
When medicine is furnished to clients living many miles from the office, where many doses may be administered, it is doubly advisable to omit poisonous drugs from the mixture. In fact, it is advisable to omit these even in city practice where the ignorant horsemen will not read or obey even the most explicit directions.

The suggestions for the possible use of belledonna and stramonium are made more for administration by the veterinarian than for use in stock colic mixtures. For a stock colic mixture which is as nearly harmless as any that can be made, and still be of value, the following is suggested:

$\mathbf{B}$

Acetanilidi Puly......................... 3 ij to iij

Ol. Menthaw Piperitae.......... 3 ij

ol. Terebinthinae.

Etheris.

Tr. Zingiberis.

Ac. Salicylici. aa $\bar{j} \mathrm{j}$ to $\mathrm{ij}$

O1. Lini................................... 3 ad. $3 i j$

M. Sig.-Give at one dose (repeat in an hour if necessary).

The acetanilid is used on account of its being a non-constipating anodyne. One that will not retard the action of eserine or arecoline, and has a beneficial influence in congestive conditions of the bowels.

Tincture of ginger is preferable to tincture of capsicum because the latter is constipating.

Spirits of nitrous ether may be used in place of the ether if desired. 


\section{Castration of Pigs Having Scrotal Hernia.*}

Cases of scrotal hernia in pigs or a rupture as the farmer calls it is a markedly hereditary condition. On some farms from year to year there are numerous. cases of this kind among the pigs; on other farms this condition is scarcely known, its presence or absence depending, as may easily be demonstrated, upon heredity.

Some farmers castrate these pigs as readily as they castrate their ordinary boar pigs, but a great many others find the operation difficult or are entirely unable to perform it and with them such pigs are usually destroyed as soon as the hernia is noted or the condition is allowed to grow worse until death results from strangulation of the intestine or from a traumatism to the scrotum.

The value of the animal is so slight that unless there is a considerable number of these ruptured pigs in the same brood or there be a very large number of hogs raised upon the place, this work can never amount to much financially, but frequently when the veterinarian is called to a farm for other work he is asked to castrate one or two or three of these pigs.

There is scarcely an operation that is more simple

"Reprinted from "Springtime Surgery," published by the American Journal of Veterinary Medicine, Evanston, II. 
than this one and yet it is one with which some veterinarians, because of their faulty technic, have experienced not a little difficulty. To throw the animal, hold him on his side and attempt to castrate him, as is done in ordinary castration is to bring on such forcible extrustion of the intestines that castration cannot be accomplished successfully, but if the pig be held up by his hind legs with his back to the holder and with his forefeet just touching the ground and possibly his neck between the ankles of the man holding him the intestines will return to the abdominal cavity of their own accord, or with slight manipulation and while held in this position castration is an exceedingly simple operation. Observe the usual aseptic precautions advisable in all minor surgery. If the inguinal aperture in the abdominal wall is very large it may be necessary to hold the testicle through the scrotum to prevent its return into the abdominal cavity along with the intestines. Should the testicle return to the abdominal cavity, lower the animal until the testicle again returns to the scrotum.

Holding the testicle between the thumb and fingers as for ordinary castration cut through the skin and dartos as for the covered operation. Strip the cellular tissue from the tunica vaginalis as close up to the internal inguinal ring as it is possible to get. Then place a ligature very tightly around the tunica vaginalis or sac including the cord, vas deferens, the arteries, veins and nerves, first making certain no portion of the intestine is included in the ligature and that it is close enough to the internal inguinal ring to prevent subse- 
quent saculation and a further escape of the intestine from the abdominal cavity. The ligation may be made with any stout cord, that has been rendered aseptic and the ends of it should be left long enough to hang slightly out of the scrotal wound. Cut off the cord with its covering membrane just back of the ligation. It is a serious mistake to incise the tunica vaginalis before the cord is ligated. Remove the other testicle and the operation is complete.

The peritoneal surfaces of the tunica vaginalis will adhere in a few hours and in a few day's that portion of the tunic below the ligation will slough off and come away together with the string with which it is tied. It is necessary to make the wound rather low so that drainage may be good. The entire operation requires less than one-half the time it takes to describe it and the mortality is practically nil.

It may be beneath the dignity of some veterinarians to charge a fee for this operation but the operation is not too insignificant to be appreciated by the owner and it is well worth while viewed from any angle. If undertaken at all of course it should be well done. 





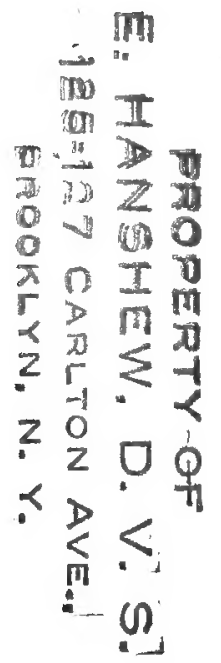


